pag

Business School

WORKING PAPER SERIES

Working Paper

2014-593

\section{Hurricane Damage Risk Assessment in} the Caribbean: An Analysis using Synthetic Hurricane Events and Nightlight Imagery

LUISITO BERTINELLI

PREEYA MOHAN

ERIC STROBL

http://www.ipag.fr/fr/accueil/la-recherche/publications-WP.html

IPAG Business School

184, Boulevard Saint-Germain

75006 Paris

France 


\title{
Hurricane Damage Risk Assessment in the Caribbean: An Analysis using Synthetic Hurricane Events and Nightlight Imagery
}

\author{
LUISITO BERTINELLI \\ CREA, University of Luxembourg \\ PREEYA MOHAN \\ SALISES, University of the West Indies \\ ERIC STROBL \\ Ecole Polytechnique \& IPAG
}

August $18^{\text {th }}, 2014$

\begin{abstract}
History has shown that hurricanes can cause catastrophic destruction and impede economic growth in the Caribbean. Nevertheless, there is essentially as of date no comprehensive quantitative risk and anticipated loss assessment for the region. In this paper we use synthetic hurricane tracks and local income proxies to estimate expected risk and losses if a climate similar to the last 30 years prevails. We show that on average, the annual fraction of expected property damage and subsequent impacts on income are nonnegligible, with large variations across islands.
\end{abstract}

Keywords: hurricane risk and damages; synthetic storm tracks; nightlight imagery. 


\section{Section I: Introduction}

Recorded Caribbean history is rich in references to the large losses in human life and property as a consequence of hurricanes, and some researchers have even argued that these have had a heavy hand in the region's lack of development (Mulcahy, 2006). However, even in modern times these storms have played an important role and possibly impeded economic prosperity. For example, it has been estimated that from 1960 to 1988 hurricanes caused more than 20,000 deaths, affected 6 million people, and destroyed property worth over US\$9.5 billion in the Greater Caribbean Basin, where the greatest destruction was to the Caribbean islands, whose small economies are least able to withstand such impacts (OFDA, 1989). Indeed studies such as Strobl (2012) have shown that such large losses have led to declines in economic growth rates. Worryingly, the frequency and intensity of hurricanes in the Caribbean seems to have been increasing in recent years, a trend that may continue with rising global temperatures (IPCC (2007) and Elsner et al. (2008)). At the same time the region has also seen ever growing economic activity in coastal areas and thus increased its exposure to potential damages from tropical storms (McGranahan, Balk, and Anderson 2007). Surprisingly, however, there is essentially no comprehensive risk and loss assessment at the national level for the region, leaving national policymakers little to base potential disaster prevention and mitigation strategies on. ${ }^{1}$

In terms of assessing expected hurricane risk and loss in the Caribbean there are methodologically essentially two challenges. Firstly, hurricanes, in particular the more extreme ones, are still in statistical terms fairly rare events, especially when one considers their likelihood of striking specific Caribbean islands.

\footnotetext{
${ }^{1}$ The only exceptions are Trepanier (2012) and Caribbean Disaster Mitigation Project (http://www.oas.org/CDMP/), but their analysis is only at the broader regional level allowing for no national specific risk assessment. Moreover, neither of these studies examines the potential costs but only examine probabilities of hurricane incidence. Ou-Yang et al (2013) calculate expected hurricane losses due to changes in climate patterns for St. Lucia.
} 
As a matter of fact, as noted by Pielke et al. (2003), hurricane occurrence has differed widely over time and space across the Caribbean. For example, while the Northern Caribbean (Bahamas, British Virgin Islands, Cayman Islands, Cuba, Dominican Republic, Haiti, Jamaica, Puerto Rico, Turks and Caicos, and US Virgin Islands) exhibits high inter-annual variability as well as large multi-decadal changes, in the Southern Caribbean (Antigua and Barbuda, Barbados, Dominica, Grenada, Guadeloupe, Martinique, Montserrat, Netherland Antilles including St. Kitts and Nevis, St. Lucia, St. Vincent and the Grenadines, and Trinidad and Tobago) there is a lower rate of hurricane strikes but similarly high multi-decadal variability. Importantly, however, using sparse historical data to derive islands' probability distribution can prove to be problematic statistically; see Emanuel and Jagger (2010). Additionally, the potential damage due to hurricanes can be very different even within islands, depending on the nature of the storm and the exposure of assets and it is important to take account of this. ${ }^{2}$ However, with regard to the latter a general problem for developing countries, and to this the Caribbean nations are no exception, is that information about the distribution of assets at the detailed spatial level is generally not available, or at least not in a consistent manner.

In this study we undertake a tropical storm risk and loss assessment of Caribbean islands explicitly addressing the two aforementioned challenges. More specifically, in order to avoid having to rely on historic hurricane tracks to estimate their probability distribution, we instead rely on a large set of synthetic tracks generated using the methodology of Emanuel et al. (2008). This allows us to derive a statistically sound distribution of hypothetical hurricane storms and accompanying wind strengths in the Caribbean according to recent climatological features. In terms of taking account of their economic impact within islands as determined by exposure, we resort to satellite derived nightlight intensity images as a proxy of

\footnotetext{
${ }^{2}$ For example, Pielke et al (2003) show that not taking into account changes in exposure over time produces very different trends of losses due to hurricanes in Cuba. Similarly, Strobl (2012) shows that in calculating out the economic impact of hurricanes for the Caribbean it is important to take account of the distribution of exposure within countries.
} 
local income. It is worth noting in this regard that nightlight images are finding increasingly more use as a measure of local income where data from official statistical sources are not available; see, for instance, Chen and Nordhaus (2011), and subsequent work by Henderson et al. (2012). As a matter of fact, in a recent study, Bertinelli and Strobl (2013) show that local nightlight intensity is able to capture the negative impact of hurricanes on local wealth in the Caribbean.

The rest of the paper is organized as follows. In Section II, the use of data on hurricane tracks and nightlight imagery is detailed. Section III outlines the wind field model and damage function employed in our analysis. Results are provided in Section IV. Section V concludes.

\section{Section II: Data}

\section{A. Sample Region}

Our sample consists of islands in the Caribbean region, both independent nations and dependent territories. These 29 islands are listed in Table 1. As can be seen, they differ substantially in size, ranging from 139,123 (Cuba) to just 27 (Saint-Barthelemy) $\mathrm{km}^{2}$. Similarly, islands such as Cuba, the Dominican Republic and Haiti have populations close to 10 million, while many of the very small islands, such as Montserrat, Saint-Barthelemy, and Anguilla have less than 20,000 inhabitants. Population density, a factor that can prove important in terms of exposure to hurricanes, also differs markedly, where the extremes are characteristic of mostly the smaller islands. For instance, the least populated islands are the Bahamas, followed by Turks and Caicos, Montserrat, and Bonaire, St Eustatius and Saba, while more densely inhabited island economies consist of Sint Maarten, Bermuda, and Saint-Martin. GDP (2012 values) is also 
fairly heterogenous, where the largest figure is found in Puerto Rico, while the value of total production is lowest in Montserrat. But these figures are clearly driven in part by the size of the population. As can be seen, the poorest island in terms of income per capita is Haiti, followed by Jamaica, Dominican Republic and Cuba, whereas the richest three are Cayman Islands, Turks and Caicos Islands, and Bonaire, St Eustatius and Saba. A similar large heterogeneity appears when one examines the GDP per sq.km figures in the fifth column of Table 1.

\section{B. Synthetic Hurricane Tracks}

Despite the fact that hurricane track data is available as far back as 1855 , the actual number of historical extreme events is not sufficient enough to derive a probability distribution with sufficient confidence at the island level. Moreover, even if the number were sufficient using the whole historical track data set, the weather driving tropical storm formation is unlikely to have been stable over the last 160 years and thus using these data to forecast future losses due to hurricanes may not be suitable.

In order to derive a probability distribution of storms and their consequent damages we here instead utilize synthetic tracks generated using the methodology of Emanuel et al (2008), which uses recent historical climate data within a coupled ocean-atmosphere tropical storm model to generate hypothetical tropical storms. More specifically, these tracks are created on the basis of meteorological global information on, amongst other things, temperature, humidity, wind and sea surface temperature. First proto-hurricanes are placed randomly in space and time and are assumed to move with the large-scale winds of a given climate state. Their intensity is then determined using a coupled ocean-atmosphere hurricane model. Eventually a small set of these storms develop into full scale hurricanes. Here this methodology was implemented to generate 4000 hurricane-strength storms traversing the Caribbean 
region on the basis of yearly weather data observed over the 1980-2010 period. ${ }^{3}$ Thus we have at hand a large set of possible hurricane-strength tropical storms in the Caribbean that might have formed if the weather was similar to the $1980-2010$ period, where each synthetic storm is assigned to one of the 30 years climatology and each year has a given expected frequency of storms. The model provides, amongst other things, the location of the eye, the forward velocity, the central pressure, and the radius of maximum winds for every two hours of a storm's lifetime. Maximum wind speed among the synthetic storms varies between 119 (which is the threshold above which a storm becomes a hurricane) and $314 \mathrm{~km} / \mathrm{hr}$, with a mean of $163 \mathrm{~km} / \mathrm{hr}$.

To generate a probability distribution of storm events we follow Emanuel (2011) and assume that the probability of each year's weather in the $1980-2010$ period is equally likely. To generate a specific year of hurricane events we then randomly picked a year and using a Poisson distribution randomly drew a set of storms from each year according to the expected frequency of events corresponding to that year. This was done a total of 100,000 times, thus providing us with a set of 100,000 possible years of hurricane occurrence. Overall, this resulted in a total of 271,065 storms, for each of which we can calculate an annual probability.

\section{B. Nightlight Imagery}

Several recent contributions, such as Chen and Nordhaus (2011), have shown that nightlight satellite imagery can be a reasonably precise proxy for economic activity (i) at the local level, and (ii) for areas/countries where data collection is considered to be inaccurate, as for instance determined by the IMF's Data Quality Assessment Framework. We thus for our purpose here, namely to approximate local

\footnotetext{
${ }^{3}$ We are very grateful to Kerry Emanuel for generating these tracks for us under the WindRiskTech hurricane model.
} 
exposure to hurricane damages, also resort to data derived from satellite images of nightlights. More specifically, since the early 1970s the Defense Meteorological Satellite Program (DMSP) has produced ground-level night time imagery, intended to provide weather and climate data, amongst other cloud cover imagery, to improve the effectiveness of military operations. Following its declassification, the data has mostly been used for civil purposes, providing a comprehensive and continuous data set of nightlight intensity to scientists, where the digital archive of this product extends back to 1992. In terms of coverage each DMSP satellite has a 101 minute near-polar orbit at an altitude of about $800 \mathrm{~km}$ above the surface of the earth, providing global coverage twice per day, at the same local time each day. ${ }^{4}$ In the late 1990 s, the National Oceanic and Atmospheric Administration (NOAA) developed a methodology to generate "stable, cloud-free nightlight data sets by filtering out transient light, such as produced by forest fires, and other random noise events occurring in the same place less than three times" from this raw data (see Elvidge et al. (1997) for a comprehensive description). Resulting images are percentages of nightlight occurrence for each pixel per year normalized across satellites to a scale ranging from 0 (no light) to 65 (maximum light). The spatial resolution of the original pictures was about 0.008 degrees on a cylindrical projection (i.e., with constant areas across latitudes) and was later converted to a polyconic projection, leading to squares of about 1 sq.km near the equator. In order to get yearly values, simple averages across daily (filtered) values of grids were generated. In the present study, we resort to data from 2012, which is the latest year of accurate data collection.

The annual nightlight data captured by these satellites essentially capture nocturnal human activity, such as electrified human settlements and gas flares, and we take this as a proxy of economic wealth - see, the

\footnotetext{
${ }^{4}$ Note that there have been so far 5 satellites covering the following sub periods: satellite ${ }^{\circ} 10: 1992-1994 ; n^{\circ} 12: 1994-1997$; $n^{\circ} 14: 1997-2003 ; n^{\circ} 15: 2000-2007 ; n^{\circ} 16: 2004-2009$. In order to handle the data during overlapping periods, we have taken, for each cell, simple averages of nightlight values across satellites.
} 
second to last column in Table 1 for sum of cell level nightlight intensity. To demonstrate its usefulness as such a measure we provide in Figure 1 a scatter plot of the logged values of nightlights per sq.km against GDP per sq.km across islands, which clearly supports the stipulated positive relationship between the two variables. We also depict the standard deviation of nightlight intensity values within islands in the last columns of Table 2. Accordingly, the distribution of nightlight intensity differs widely in the Caribbean, being highest in Curaco and Trinidad and Tobago, and lowest in Dominica, Haiti, and Montserrat.

\section{Section III: Hurricane Destruction Index}

\section{A. Wind Field Model}

The next step is to use the synthetic storm tracks in conjunction with a wind field model to generate wind speeds experienced at any point within islands that can then be translated into potential damage associated with each storm at that point. To calculate the wind speed experienced due to storm $j$ at any point $P=i$ at any time $t$, i.e., $V_{i j t}$, we use Boose et al's (2004) version of the well-known Holland (1980) wind field model:

$V_{i j t}=G \cdot F \cdot\left[V_{m, j t}-S \cdot\left(1-\sin \left(T_{i j t}\right)\right) \cdot \frac{V_{h, j t}}{2}\right] \cdot\left[\left(\frac{R_{m, j, t}}{R_{i t}}\right)^{B_{j t}} \cdot \exp \left(1-\left[\frac{R_{m, j, t}}{R_{i t}}\right]^{B_{j t}}\right)\right]^{\frac{1}{2}}$

where $V_{m}$ is the maximum sustained wind velocity anywhere in the hurricane. $T$ is the clockwise angle between the forward path of the hurricane and a radial line from the hurricane center to the point of interest, $P=i, V_{h}$ is the transition speed of the hurricane, $R_{m}$ is the radius of maximum winds, $R$ is the radial distance from the center of the hurricane to point $P$. The remaining ingredients consist of the gust factor $G$ 
and the scaling parameters $F, S$, and $B$, for surface friction, asymmetry due to the forward motion of the storm, and the shape of the wind profile curve, respectively.

In terms of implementing (1) one should note that $V_{m}$ is given by the storm track data, $V_{h}$ can be directly calculated by following the storm's movements between locations, and $R$ and $T$ are calculated relative to the point of interest $P=i$. All other parameters have to be estimated or assumed. In this regard, one should note that we have no information on the gust wind factor $G$. However a number of studies suggest that it will generally vary around 1.5, which is also the value used by Boose et al. (2004) and hence we similarly assume it to be 1.5 (see, for instance, Paulsen and Schroeder (2005)). Furthermore, we have no information on the surface friction to directly determine F. However, in their review of tropical storm hazard modeling Vickery et al. (2009) noted that in open water the reduction factor was about 0.7, corresponding to a wind speed reduction of approximately 14 per cent on the coast and 28 per cent $50 \mathrm{~km}$ inland. We thus adopted a reduction factor that linearly decreased within this range as we considered points further inland from the coast. As Boose et al. (2004) we assume $S$ to take on a value of 1.

In terms of the remaining parameters, Vickery and Wadhera (2008) noted that the radial pressure profile parameter $B$ and the radius maximum winds play an important role in estimating local wind speeds. While the synthetic track data provides a measure of radius of maximum wind speed, we need to estimate the value of $B$. More specifically, for $B$ we employ Holland (2008)'s approximation method:

$$
B=b_{s}(G)^{2} \approx 1.5^{2} b_{s}
$$

with $b_{s}=-4.4 x 10^{-5} \Delta p^{2}+0.01 \Delta p+0.03 \frac{\partial p_{c}}{\partial t}-0.014 \psi+0.15 V_{h}^{x}+1.0$ 
and

$$
x=0.6\left(1-\frac{\Delta p}{215}\right)
$$

where $\Delta p$ denotes the pressure drop due to the cyclone center, $\delta p_{c} / \delta t$ is the intensity change, $\Psi$ is the absolute value of latitude, $V_{h}$ is the cyclone transition speed, and $G$ is the conversion factor from gradient to surface wind. ${ }^{5}$

Given the hurricane track data and the assumed parameters, as just outlined, equations (1) through (4) allow us to estimate the wind speed experienced at any point $i$, in our case the centroid of each nightlight cell, for each hurricane at each point during its lifetime.

\section{B. Damage Function}

In terms of translating wind speeds into potential damage, as noted by Emanuel (2011), while property damage due to tropical storms should vary with the cubic power of the wind speed experienced on physical grounds, ${ }^{6}$ there is normally a threshold below which there is unlikely to be any substantial physical damage. Moreover, the fraction of property damaged should approach unity at a very high wind speed. To capture these features he proposes the following index, $f$, proxying the fraction of property damage:

$f_{i j}=\frac{v_{n, i j}^{3}}{1+v_{n, i j}^{3}}$

where

\footnotetext{
${ }^{5}$ One may want to note that Holland (1980) uses a value of 1.6 for this conversion factor. We here instead use 1.5 in order to be consistent with the value we use for $G$ in (2). Using instead 1.6 made no noticeable qualitative or quantitative difference to our results.

${ }^{6}$ As noted by Emanuel (2005), both the monetary losses in hurricanes as well as the power dissipation of these storms tend to rise roughly as the cube of the maximum observed wind speed. Furthermore, there are physical energy dissipation grounds for using wind speed to the cubic power; see, for instance, Andrews (2010).
} 


$$
v_{n, i j}=\frac{\operatorname{MAX}\left[\left(V_{i j}-V_{\text {thressh }}\right), 0\right]}{V_{\text {half }}-V_{\text {thresh }}},
$$

where $V_{i j}$ is the wind experienced at point $i$ due to storm $j$ as calculated in (1), $V_{\text {thresh }}$ is the threshold below which no damage occurs, and $V_{\text {half }}$ is the threshold at which half of the property is damaged. As in Emanuel et al (2012) we use a value of $93 \mathrm{~km}$ (i.e., $50 \mathrm{kts}$ ) for $V_{\text {thres }}$ and a value of $210 \mathrm{~km}$ (i.e., $110 \mathrm{kts}$ ) for $V_{\text {half. }}$ One may want to note that the choice of $V_{\text {thresh }}$ at $93 \mathrm{~km}$ seems in line with findings by FEMA (2010) who estimated damages across a large number of building types, distinguished by use, size, roof type and construction, wall type and construction, and the presence of a garage. The value for 50 per cent of damage, i.e., $V_{\text {half, }}$ is in contrast, much more sensitive to the type of building; again, see FEMA (2010). We surveyed all damage curves estimated by FEMA (2010) and found that the value of $210 \mathrm{~km}$ corresponded roughly to the lower bound of the loss and content ratio across building types and surface roughness values, where the value was obviously lower for the buildings build with less sturdy materials and lower surface. ${ }^{7}$ Thus this value seems reasonable for the Caribbean where in general the type of housing present is not very hurricane resistant; see Prevatt et al (2010) for a review.

We depict the damage profiles of $f$ in Figure 2, as well as three bars reflecting the wind associated with Saffir-Simpson Scales 1,3 , and $5 .{ }^{8}$ As can be seen, wind speeds classified as level $1(119 \mathrm{~km} / \mathrm{hr}), 3$ $(178 \mathrm{~km} / \mathrm{hr})$, and $5(252 \mathrm{~km} / \mathrm{hr})$ correspond to about $0.011,0.277$, and 0.715 values of $f$.

\footnotetext{
${ }^{7}$ For instance, this value corresponded to the building loss ratio for a two story building with gable roof, $6 \mathrm{~d}$ roof sheathing nails, shingle roof cover, wood frame walls, toe-nailed roof/wall connections with no garage.

${ }^{8}$ According to the NOAA scale 1 corresponds to "No real damage to building structures. Damage primarily to unanchored mobile homes, shrubbery, and trees. Also, some coastal road flooding and minor pier damage", scale 3 to "Some structural damage to small residences and utility buildings with a minor amount of curtain wall failures. Mobile homes are destroyed. Flooding near the coast destroys smaller structures with larger structures damaged by floating debris. Terrain continuously lower than 5 feet ASL may be flooded inland 8 miles or more.", and scale 5 to "Complete roof failure on many residences and industrial buildings. Some complete building failures with small utility buildings blown over or away. Major damage to lower floors of all structures
} 
In order to arrive at an annual percentage of damage for a hypothetical year we simply take the maximum value of $f$ for each nightlight cell for each simulated storm as the total damage due to the simulated storm for that cell. Our island level proxy of damage for a synthetic hurricane is then simply the sum of all maximal $f_{i}$ in a given island, weighted by the share of nightlight (in 2012) in area $i$ with respect to total nightlight in the given island:

$F=\sum_{i \in k} \frac{n l_{i}}{N L_{k}} \cdot \max _{j}\left\{f_{j}\right\}$

where $N L_{k}=\sum_{i \in k} n l_{i}$ and $k$ represents a Caribbean island $k$ or, alternatively, the whole Caribbean island region.

\section{Risk and Loss Statistics}

Upon completion of calculating the wind speed for each nightlight cell in our data set and inserting the values in (6) and (7), one can rank order the values of $F$ per island or the region to define a loss probability distribution as:

$P(F>\bar{F})=1-\sum_{x=0}^{\infty} P(F<\bar{F} \mid x) p(x)$

where $P(F<\overline{F \mid x})$ is the probability that individual storm damage, $F$, is less than $\bar{F}$ given that $\mathrm{x}$ storms occur and $p(x)$ is the probability that $x$ storms occur during a year. The inverse of $(8)$ is then just the return period (in years), $R P$, of a storm with damage of at least $\bar{F}$. Expected annual damages of at least $\bar{F}$ are then just:

located less than 15 feet ASL and within 500 yards of the shoreline." URL: http://www.erh.noaa.gov/box/Saffir.html accessed April 23, 2014. 


$$
\operatorname{EXP}(F \mid F>\bar{F})=\sum_{x=0}^{\infty} F * P(F<\overline{F \mid x}) p_{t}(x)
$$

\section{Section IV: Results}

\section{A. Damage Risk}

In Table 2 we present the results of our risk and loss assessment analysis. More precisely, the first column contains the annual probability of damage due to hurricane occurrence, i.e., $P(F>0)$ from (8). As can be seen from the last row of the table, there is an essentially certain probability that at least one island in the Caribbean will be affected by a hurricane. This probability of a damaging storm and corresponding return periods, however, differ substantially across islands, which demonstrates the danger of inferring island probabilities from regional analysis. For example, countries like Cuba and Bahamas should expect a nearly 70 percentage point annual chance of a damaging hurricane occurring, whereas this is multiple times smaller for islands like Aruba, Bermuda, and Curaçao. In terms of return periods, this translates into relatively long return periods for the latter three countries, standing at 44,19 , and 45 years, respectively. In contrast, the Bahamas, Cuba, Haiti, and Puerto Rico should expect a damaging storm to arise in less than 5 years.

Of course, given that many of the islands are on average many multiple times larger than others, the probability of a hurricane making landfall on their shore or coming near to it is mechanically increased. In Figure 2, we have thus plotted the probability of damage against the log of the area, which indeed supports a positive relationship between both variables. In order to investigate this more deeply we employed a simple regression analysis where we regressed the return period of an island on a number of explanatory 
factors that can be calculated from our data base. Firstly, we include the standard deviation of nightlight intensity $(N L(S D))$ as well as the total share of non-zero cells (SHARE_NZ) within islands in order to capture concentration of activity within islands. In order to control for the area exposed of an island(s) we use both its total area (AREA) as well as the area of the minimum rectangle to contain it (AREA_SPAN). One should note that this latter aspect allows one to take account of the fact that some island(s) consist of a set of several, possibly dispersed, land areas. Finally, we also identified the rectangular area within which 50 per cent of all our synthetic hurricane points are contained in, and created an indicator variable (HURR_SPAN) that takes on the value of one if an island(s) lies at least partially within this region, and zero otherwise.

The results of regressing the return period of islands, using a negative binomial regression model due to the count nature of the dependent variable, on our controls are displayed in Table 3 . As can be seen, neither the share of non-zero cells nor the standard deviation of cells act to predict the number of years within which to expect a damaging hurricane across islands. In contrast, being part of the region through which a large part of the synthetic tracks travers is associated with differences in estimated return periods across the islands. More specifically, if one calculates out the marginal effect, then location in this storm prone region decreases the return period by about 4 years.

Finally, although not reported here, one may want to note that when analyzing the probabilities at the cell level the variance of the probabilities of suffering from hurricane damages is larger within than between island countries. As a matter of fact, a simple variance decomposition of these probabilities by our 1sq. km area grids indicates that roughly 24 per cent of total variance is explained by inter-island variation, the rest being due to intra-island differences. Arguably, this latter result supports the approach adopted 
here, as it highlights the importance of adopting a geographically disaggregated focus when assessing the potential impact of hurricanes. ${ }^{9}$

\section{B. Damage Extent}

Of course, it is not only the occurrence of a damaging hurricane strike but also its extent that matters when it occurs, i.e., $\operatorname{EXP}(F \mid F>0)$. As can be seen in the third column of Table 2, the expected percentage of assets damage is small as a share of the total in the Caribbean. This is not surprising given that any hurricane is likely to only affect a small portion of all Caribbean islands as it traverses the region. However, comparing individual territories it becomes clear that there are a number that are likely to experience considerably more damage than others if a hurricane occurs. For example, Anguilla, Cayman Islands, Jamaica, Saint-Martin, and Sint Maarten all would experience an average damage of 2 per cent (i.e., 2 per cent of property would be damaged) in case of a damaging hurricane. One may want to note that the extent of damages appears does not seem to rise with a greater probability of a damaging hurricane - the overall correlation between the probability and the extent of damage is negative $(-0.4618)$ and significant at 5 per cent. We thus compute the annual expected $F$ index, i.e., $\operatorname{EXP}(F \mid F \geq 0)$, for the region and each Caribbean island. Accordingly, the value, unsurprisingly for reasons noted above, is small for the overall region. In terms of the individual territories, Guadeloupe and Cayman Islands are exposed to the largest expected damages, which are about twice as high as the average damages in the remaining countries, but 35 times higher than Aruba's expected damages.

As with the return period we also investigate which island-specific factors can act as predictors of their values and run a similar regression analysis in the second and third column of Table $3 .^{10}$ Accordingly.

\footnotetext{
${ }^{9}$ This was already suggested by the study by Bertinelli and Strobl (2013) which showed that not allowing for intra-island hetereogeneity leads to a substantial under-estimation of the impact of hurricanes on island economic growth rates.
} 
size, both in area and geographical extent, of islands reduce the expected extent of damage if a hurricane occurs. This is not surprising as tropical storms are relatively local phenomena, so that for larger ones it is more likely that the extent of damages due to hurricanes will differ across areas. We also find that the standard deviation of nightlight values of cells is negatively correlated and the share of non-zero cells is positively correlated with F. Again this makes intuitive sense - the more spread human settlements are within islands the less likely that a non-populated area will be hit if a hurricane strikes. In contrast, none of our controls act to significantly predict the expected value of $F$; see column 3 of Table 3.

In order to describe the distribution of the extent of damage with the associated probabilities, we plot $F$ against the return period for each values by island in Figures $4(i)$ to (v). In this regard, if one considers a 100-year return period, then there are only a few countries for which we expect a hurricane with damages of at least 10 per cent, namely, Guadeloupe, Cayman Islands, and Jamaica. For all other islands the expected return period of such a damaging storm is considerably longer. In terms of 500-year events, there are only a few islands - Saint-Martin, Cayman Islands, Anguilla, Saint Lucia, Jamaica, and Dominica - for which this would entail 30 per cent damage.

\section{Monetary Values}

We have thus far provided an estimate of the impact of hurricane landfall in terms of the units of potential damages generated by wind. However, ideally one would also like to put a monetary value on the percentage damage figures. In order to translate our potential destruction measures into economic values, we follow Chen and Nordhaus (2011) and Henderson et al. (2012) and estimate the following specification:

$$
\log \left(G D P / A R E A_{k, t}\right)=\alpha+b_{1} \log (N L / A R E A)_{k, t}+b_{2} \log (N L / A R E A)_{k, t}^{2}+\eta_{k}+\tau_{t}+\omega_{k t},
$$

\footnotetext{
${ }^{10}$ Given that $F$ varies between 0 and 1 we employ a fractional probit model for both of these.
} 
where the left hand side is the logged value of Gross Domestic Product per sq.km (GDP/AREA) in country $i$ at time $t, \mathrm{NL} / \mathrm{AREA}$ is the average cell value of nightlight intensity, $\eta$ is a country specific indicator variable, $\tau$ is a year specific indicator variable, and $\omega$ is a standard error term. Our coefficients of interest to translate units of nightlights into monetary values are given by $\alpha$ and the $B^{\prime}$ s. Using the nightlight figures for every grid of our islands, on can next calculate the annual monetary value damage associated with hurricane strikes as:

$\operatorname{LOSS}_{k}=\sum_{i \in k} \mid \alpha+\beta_{1} \log (\text { Nightlight / area })_{i, k}+\beta_{2} \log (\text { Nightlight / area })_{i, k}^{2} \mid \times f_{i, k}$

where $\alpha, b_{1}$, and $b_{2}$ are the coefficients estimated in (10) above, and $f$ is from (5) and measures the proportion of damaged belongings, and $i$ and $k$ indexes countries and grid cells, respectively.

In order to estimate (10) for all countries in our sample we take GDP data for Caribbean countries from the Penn World Tables (PWT), which is also the source of GDP data for Henderson et al. (2011), and supplement these with data on GDP from Bulmer-Thomas (2012) for the islands/territories not covered in the PWT. To generate a nightlight measure at the country level, we, similarly to the previous authors, aggregate up grid level data and divide these by their total area. In estimating (10) we find that $\alpha=16.8, b_{1}$ $=0.265$, and $B_{2}=0.044$, all significant at the 1 per cent level. ${ }^{11}$

Results derived rom (11) are given in the three last columns of Table 32 As can be seen, when a hurricane strikes total losses, i.e., $\operatorname{EXP}($ LOSS/LOSS $>0)$, are likely to be around 187 million for the region. In terms of individual islands, damages would constitute around 20 million for a number of countries, namely, the Bahamas, the Cayman Islands, Guadeloupe, Jamaica, Puerto Rico, and Saint Lucia. In contrast, total

\footnotetext{
${ }^{11}$ Their robust standard errors were $0.017,0.007$, and 0.065 , respectively.
} 
losses would be less than 3 million for islands such Aruba, Bermuda, Bonaire, Saint Eustatius and Saba, and Curacao. Expected annual losses (EXP(LOSS/LOSS $\geq 0))$ are about 104 million for the region in total, but again differ substantially across islands. More precisely, these are largest for the Bahamas (13.1 million), followed, by Cuba (6.9 million), Puerto Rico (6.6 million) and Dominican Republic (6.2 million). If we regress conditional losses and expected annual losses on our set of covariates - see the last four columns of Table 3 - one discovers that the consistently significant predictor is country wealth, whether measured in terms of GDP or nightlight intensity. For the annual expected losses that a greater share of non-zero cells decreases losses, thus again suggesting that more concentrated spatial economic wealth will result on average in greater yearly hurricane destruction.

Finally, we use our damage and probability data to derive return periods of expected damages across the Caribbean island region and graph this in Figure 5. As can be seen, our synthetic tracks and damage index suggest that a 50-year event is likely to cost around 8 billion $\$$ US dollars to the region, while a hundred year even is estimated to be about 12 billion. Every 500 years one may expect a hurricane to cause about 30 billion \$US dollars in damages in the Caribbean.

\section{Section V: Conclusions}

Historical experience suggests that about 11 tropical storms form in the Atlantic Basin, and thus potentially threatening Caribbean islands, every year. Of these, on average 6 reach hurricane strength and a further 2 become damaging hurricanes. If we consider these rough figures in terms of potential risk and losses to individual islands in the Caribbean, then it is clear that they are relatively rare, although potentially very destructive events, so that historical data is not sufficient enough to derive distributions for 
these. Moreover, for areas like the Caribbean, there is little information on local exposure, a factor that has been shown to be important in terms of driving losses when an event occurs. To overcome these challenges we in this paper employed synthetic hurricane track data generated under recent weather conditions within a wind field model as well as satellite derived proxies of local exposure to determine local, i.e., within islands, distributions of wind speeds and damages. These were then summed to obtain regional and island aggregate estimates. Our results suggested that costs could potentially be substantial for the region, with a 50-year event expected to cost about 8 billion \$US dollars. However, risks and losses are likely to differ widely across islands, where island size seems to driving differences in risk, total wealth contributes to total estimated monetary losses, but spatial concentration of economic wealth also seems to play a role.

Our analysis could be extended on a number of fronts. Clearly using a simple wind field model with synthetic hurricane tracks, while relatively easy to implement, simplifies the true nature of damages due to hurricanes, ignoring other facets of destruction like storm surge and flooding. While storm and excessive rainfall have been shown to be correlated with greater winds experienced during a hurricane, explicitly modeling these factors would result in greater precision in our estimates. Secondly, our translation of local wind speeds experienced for a particular hypothetic storm is based on a somewhat stylized damage function, so that further refinement of these for the Caribbean could also be a further direction for future research. It must also be noted that our measure of local asset exposure is probably more likely to capture wealth attributable to residential settlements and manufacturing and service sector economic activity, but less likely to capture agriculture. Moreover, we are solely focusing on direct damages and are unable to capture indirect losses. Finally, our analysis is based on recent weather patterns and thus likely only to be 
good in terms of short-term forecasts. For a longer term robust analysis one might want to consider using synthetic tracks generated under different climate change scenarios. 


\section{$\underline{\text { References }}$}

[1] Andrews, DA. (2010), "An Introduction to Atmospheric Physics", $2^{\text {nd }}$ ed. Cambridge University Press, 237 pp.

[2] Bertinelli, L. and E. Strobl (2013), "Quantifying the Local Economic Growth Impact of Hurricane Strikes: An Analysis from Outer Space for the Caribbean", Journal of Applied Meteorology and Climatology, 52(8): 1688-1697.

[3] Boose, E., M. Serrano, and D. Foster (2004), "Landscape and Regional Impacts of Hurricanes in Puerto Rico", Ecological Monograph, 74(2): 335-352.

[4] Bulmer-Thomas (2012), "The Economic History of the Caribbean Since the Napoleonic Wars", New York, Cambridge University Press, Cambridge.

[5] CDERA - CDB (Caribbean Disaster Emergency Response Agency - Caribbean Development Bank (2003). Model national hazard mitigation policy for the Caribbean. Caribank document.

[6] Chen, X. and W. Nordhaus (2011), "Using luminosity data as a proxy for economic statistics", Proceedings of the National Academy of Science, 108(21): 8589-8594.

[7] Elsner, J. B., J. P. Kossin, and T. H. Jagger (2008), "The increasing intensity of the strongest tropical cyclones", Nature, 455: 92-95.

[8] Elvidge, C.D., Baugh, K.E., Kihn, E.A., Kroehl, H.W. and Davis, E.R. (1997), Mapping city lights with nighttime data from the DMSP Operational Linescan System. Photogrammetric Engineering and Remote Sensing, 63, 727-734.

[9] Emanuel, K. (2005), "Increasing destructiveness of tropical cyclones over the past 30 years", Nature, 436, 686-688.

[10] Emanuel, K. (2011), "Global warming effects on U.S. hurricane damage", Weather, Climate, and Society, 3, 261-268.

[11] Emanuel, K., K. Speer, R. Rotunno, R. Srivastava, and M. Molina (1995), Hypercanes: A possible link in global extinction scenarios", Journal of Geophysical Research (Atmospheres), 100(7): 13755-13765.

[12] Emanuel, K., R. Sundararajan, and J. Williams (2008), "Hurricanes and Global Warming: Results from Downscaling IPCC AR4 Simulations", Bulletin of the American Meteorological Society, 89(3): 347-367.

[13] Emanuel, K. and T. Jagger (2010), "On Estimating Hurricane Return Periods", Journal of Applied Meteorology and Climatology, 49: 837-844.

[14] Emanuel, K., F. Fondriest, and J. Kossin (2012), "Potential economic value of seasonal hurricane forecasts", Weather, Climate, and Society, 4, 110-117.

[15] Federal Emergency Management Authority [FEMA] (2010). HAZUS- MH MR5 Technical Manual. Washington, D.C.

[16] Henderson, J. V., A. Storeygard, and D.N. Weil (2012), "Measuring economic growth from outer space", American Economic Review, 102(2): 994-1028. 
[17] Holland, G. (1980), "An Analytic Model of the Wind and Pressure Profiles in Hurricanes", Monthly Weather Review, 106, 1212-1218.

[18] Holland, G. (2008), "A revised hurricane pressure-wind model", Monthly Weather Review, 136, 3432-3445.

[19] IPCC (2007), "Climate Change 2007: The Physical Science Basis. Contribution of Working Group I to the Fourth Assessment Report of the Intergovernmental Panel on Climate Change", Solomon, S, D. Qin, M. Manning, Z. Chen, M. Marquis, KB. Averyt, M. Tignor, and HL. Miller (Eds.), Cambridge University Press, Cambridge, UK.

[20] McGranahan, G., D. Balk, B. Anderson (2007), "The rising tide: Assessing the risks of climate change and human settlements in low elevation coastal zones", Environment and Urbanization, 19(1): 17-37.

[21] Mulcahy, M. (2006), "Hurricanes and Society in the British Greater Caribbean, 1624-1783", Johns Hopkins University Press, Baltimore, 257pp.

[22] OFDA - Office of Foreign Disaster Assistance, U.S. Agency for International Development (1989). Disaster History: Significant Data on Major Disasters Worldwide, 1900-Present. Washington, D.C.: OFDA/USAID.

[23] Ou-Yang, C., Kunreuther, H. and Erwann, M.K. (2013). "An Economic Analysis of Climate Adaptations to Hurricane Risk in St. Lucia”, The Geneva Papers, 38, pp. 521-546.

[24] Paulsen, BM. and JL. Schroeder (2005), "An Examination of Tropical and Extratropical Gust Factors and the Associated Wind Speed Histograms", Journal of Applied Meteorology, 44(2), 270-280.

[25] Pielke, R. A., J. Rubiera, C. Landsea, ML. Fernandez, and R. Klein (2003), "Hurricane vulnerability in Latin America and the Caribbean: Normalized damage and loss potentials", Natural Hazards Review, 4(3): 101-114.

[26] Prevatt, D.O., Dupigny-Giroux, L.A., and Masters, F.J. (2010). "Engineering Perspectives on Reducing Hurricane Damage to Housing in CARICOM Caribbean Islands", Natural Hazards Review, 11 (4), pp. 140150.

[27] Trepanier, J. (2012), "Quantifying extreme hurricane risk in the North Atlantic and Gulf of Mexico", PhD dissertation, Department of Geography, Florida State University.

[28] Vickery, P.J., D. Wadhera (2008), "Statistical models of Holland pressure profile parameter and radius to maximum winds of hurricanes from flight level pressure and H*Wind data", Journal of Applied Meteorology and Climatology, 47(10), 2417-2497.

[29] Vickery, P., D. Wadhera, M. Powell, and Y. Chen (2009), “A Hurricane Boundary Layer and Wind Field Model for Use in Engineering Applications", Journal of Applied Meteorology and Climatology, 48(2): 381-405. 
Table 1: Summary Statistics

\begin{tabular}{|c|c|c|c|c|c|c|c|c|}
\hline ISLAND & POP & AREA & POP/AREA & GDP & GDP/AREA & GDP/POP & NL & NL(st.dev.) \\
\hline Anguilla & 15754 & 101 & 156 & 343.4 & 3.4 & 21798 & 2073 & 13 \\
\hline Antigua and Barbuda & 90156 & 523 & 172 & 2144.3 & 4.1 & 23784 & 10355 & 20 \\
\hline Aruba & 109153 & 216 & 505 & 3024.0 & 14.0 & 27704 & 7903 & 20 \\
\hline Bahamas & 319031 & 17112 & 19 & 9269.8 & 0.5 & 29056 & 41413 & 9 \\
\hline Barbados & 288725 & 521 & 554 & 6252.0 & 12.0 & 21654 & 19831 & 17 \\
\hline Bermuda & 69467 & 96 & 724 & 1920.0 & 20.0 & 27639 & 3780 & 14 \\
\hline Bonaire, St Eustatius \& Saba & 21133 & 386 & 55 & 2817.8 & 7.3 & 133336 & 3086 & 11 \\
\hline British Virgin Islands & 31912 & 214 & 149 & 1091.4 & 5.1 & 34200 & 3127 & 14 \\
\hline Cayman Islands & 53737 & 351 & 153 & 4914.0 & 14.0 & 91445 & 7628 & 19 \\
\hline Cuba & 11061886 & 139123 & 80 & 63137.5 & 0.5 & 5708 & 494717 & 7 \\
\hline Curaçao & 146836 & 528 & 278 & 5068.8 & 9.6 & 34520 & 14131 & 23 \\
\hline Dominica & 73286 & 913 & 80 & 662.3 & 0.7 & 9037 & 3912 & 4 \\
\hline Dominican Republic & 10219630 & 59408 & 172 & 45373.6 & 0.8 & 4440 & 287309 & 9 \\
\hline Grenada & 109590 & 426 & 257 & 1192.8 & 2.8 & 10884 & 6711 & 12 \\
\hline Guadeloupe & 405739 & 2009 & 202 & 12254.9 & 6.1 & 30204 & 45584 & 17 \\
\hline Haiti & 9893934 & 33425 & 296 & 4798.8 & 0.1 & 485 & 33499 & 4 \\
\hline Jamaica & 2909714 & 13523 & 215 & 12547.1 & 0.9 & 4312 & 153543 & 11 \\
\hline Martinique & 386486 & 1341 & 288 & 11130.3 & 8.3 & 28799 & 43677 & 18 \\
\hline Montserrat & 5189 & 125 & 42 & 63.2 & 0.5 & 12180 & 520 & 4 \\
\hline Puerto Rico & 3645648 & 11022 & 331 & 80460.6 & 7.3 & 22070 & 380953 & 19 \\
\hline St Kitts and Nevis & 51134 & 324 & 158 & 907.2 & 2.8 & 17742 & 5450 & 13 \\
\hline St Lucia & 162781 & 742 & 219 & 1855.0 & 2.5 & 11396 & 12279 & 13 \\
\hline St Vincent. \& the Grenadines & 103220 & 470 & 220 & 1316.0 & 2.8 & 12749 & 4830 & 10 \\
\hline Saint-Barthélemy & 7298 & 27 & 270 & 253.8 & 9.4 & 34777 & 799 & 15 \\
\hline Saint-Martin & 31264 & 71 & 440 & 596.4 & 8.4 & 19076 & 3592 & 12 \\
\hline Sint Maarten & 39689 & 44 & 902 & 792.0 & 18.0 & 19955 & 2424 & 10 \\
\hline Trinidad and Tobago & 1225225 & 6134 & 200 & 20242.2 & 3.3 & 16521 & 176299 & 22 \\
\hline Turks and Caicos Islands & 47754 & 1259 & 38 & 5539.6 & 4.4 & 116003 & 5483 & 11 \\
\hline Virgin Islands, U.S. & 104737 & 439 & 239 & 4214.4 & 9.6 & 40238 & 15970 & 20 \\
\hline
\end{tabular}

Notes: AREA: land area in $\mathrm{km}^{2}$; POP: population; AREA/POP: population per $\mathrm{km}^{2}$; GDP: gross domestic product in millions of 2012 \$US dollars; GDP/AREA: GDP per $\mathrm{km}^{2}$ in millions of 2012 \$US dollars; GDP/POP: GDP per capita in 2012 \$US dollars. 
Table 2: Risk and Loss Assessment Results

\begin{tabular}{|c|c|c|c|c|c|c|}
\hline ISLAND & $P R(F>0)$ & RP & $\operatorname{EXP}(F \mid F>0)$ & $\operatorname{EXP}(F \mid F \geq 0)$ & $\operatorname{EXP}(L O S S \mid L O S S>0)$ & $\operatorname{EXP}(L O S S \mid L O S S \geq 0)$ \\
\hline Anguilla & 0.10 & 10 & 0.019 & 0.0018 & 12.8 & 1.2 \\
\hline Antigua and Barbuda & 0.12 & 9 & 0.008 & 0.0010 & 6.9 & 0.8 \\
\hline Aruba & 0.02 & 44 & 0.008 & 0.0002 & 1.0 & 0.0 \\
\hline Bahamas & 0.65 & 2 & 0.004 & 0.0029 & 20.1 & 13.1 \\
\hline Barbados & 0.11 & 9 & 0.016 & 0.0017 & 11.4 & 1.2 \\
\hline Bermuda & 0.05 & 19 & 0.007 & 0.0004 & 2.6 & 0.1 \\
\hline Bonaire, St Eustatius \& Saba & 0.14 & 7 & 0.004 & 0.0005 & 2.8 & 0.4 \\
\hline British Virgin Islands & 0.16 & 6 & 0.013 & 0.0021 & 14.8 & 2.4 \\
\hline Cayman Islands & 0.16 & 6 & 0.023 & 0.0037 & 21.3 & 3.5 \\
\hline Cuba & 0.63 & 2 & 0.003 & 0.0021 & 10.9 & 6.9 \\
\hline Curaçao & 0.02 & 45 & 0.012 & 0.0003 & 1.3 & 0.0 \\
\hline Dominica & 0.15 & 7 & 0.020 & 0.0029 & 12.8 & 1.9 \\
\hline Dominican Republic & 0.41 & 3 & 0.006 & 0.0025 & 15.3 & 6.2 \\
\hline Grenada & 0.16 & 6 & 0.011 & 0.0017 & 11.6 & 1.8 \\
\hline Guadeloupe & 0.16 & 6 & 0.019 & 0.0031 & 21.7 & 3.5 \\
\hline Haiti & 0.28 & 4 & 0.008 & 0.0023 & 13.3 & 3.7 \\
\hline Jamaica & 0.16 & 6 & 0.022 & 0.0036 & 18.7 & 3.1 \\
\hline Martinique & 0.14 & 7 & 0.014 & 0.0020 & 14.6 & 2.1 \\
\hline Montserrat & 0.10 & 10 & 0.015 & 0.0016 & 8.1 & 0.9 \\
\hline Puerto Rico & 0.30 & 3 & 0.010 & 0.0029 & 21.6 & 6.6 \\
\hline St Kitts and Nevis & 0.12 & 9 & 0.011 & 0.0012 & 8.8 & 1.0 \\
\hline St Lucia & 0.13 & 8 & 0.025 & 0.0033 & 19.6 & 2.6 \\
\hline St Vincent. \& the Grenadines & 0.19 & 5 & 0.006 & 0.0012 & 6.3 & 1.2 \\
\hline Saint-Barthélemy & 0.09 & 12 & 0.014 & 0.0013 & 9.5 & 0.8 \\
\hline Saint-Martin & 0.09 & 11 & 0.020 & 0.0019 & 14.7 & 1.4 \\
\hline Sint Maarten & 0.09 & 12 & 0.022 & 0.0019 & 14.7 & 1.3 \\
\hline Trinidad and Tobago & 0.22 & 5 & 0.012 & 0.0026 & 17.4 & 3.9 \\
\hline Turks and Caicos Islands & 0.17 & 6 & 0.012 & 0.0020 & 13.9 & 2.3 \\
\hline Virgin Islands, U.S. & 0.19 & 5 & 0.011 & 0.0021 & 15.1 & 2.9 \\
\hline REGION & 1.00 & 1 & $16.6^{*} 10^{-6}$ & $9.3 * 10^{-4}$ & $187.2 * 10^{3}$ & $104.4 * 10^{3}$ \\
\hline
\end{tabular}

Notes: $P R(F>0)$ : probability that a damaging hurricane occurs; RP: return period of a damaging hurricane; $F$ : Country level $f$ index if a damaging hurricane occurs; EXP(F): annual expected value of $f$ : LOSS: estimated monetary losses (in millions of 2012 \$US dollars) if a damaging hurricane occurs; EXP(LOSS): estimated annual monetary losses (in millions of 2012 \$US dollars). 
Table 3: Determinants of Risk and Loss Factors - Regression Analysis

\begin{tabular}{|c|c|c|c|c|c|c|c|}
\hline & (1) & (2) & (3) & (4) & (5) & (6) & (7) \\
\hline DEP. VAR: & $\mathbf{R P}$ & $\operatorname{EXP}(F \mid F>0)$ & $\operatorname{EXP}(F \mid F \geq 0)$ & LOSS & EXP(LOSS) & LOSS & EXP(LOSS) \\
\hline \multirow[t]{2}{*}{$N L(S D)$} & 0.0334 & $-0.0105^{*}$ & -0.00304 & $-95,508$ & 18,150 & $-92,479$ & 28,967 \\
\hline & (0.0298) & $(0.00570)$ & $(0.00728)$ & $(308,376)$ & $(65,560)$ & $(298,891)$ & $(64,205)$ \\
\hline \multirow[t]{2}{*}{ SHARE_NZ } & 0.0384 & $0.268 * *$ & -0.00690 & $-360,056$ & $-3.134 e+06^{*}$ & $-1.560 e+06$ & $-3.562 e+06 *$ \\
\hline & $(0.461)$ & $(0.104)$ & $(0.111)$ & $(4.557 e+06)$ & $(1.724 e+06)$ & $(4.434 \mathrm{e}+06)$ & $(1.719 e+06)$ \\
\hline \multirow[t]{2}{*}{ AREA } & $-9.83 e-06 * *$ & $-1.50 e-06^{*}$ & 8.07e-07 & -69.21 & -24.40 & $-131.5^{*}$ & -45.77 \\
\hline & $(4.92 \mathrm{e}-06)$ & (8.66e-07) & (1.07e-06) & (57.68) & (31.96) & $(71.17)$ & $(33.58)$ \\
\hline \multirow[t]{2}{*}{ AREA_SPAN } & $-2.19 e-06^{* *}$ & $-7.59 \mathrm{e}-07^{* * *}$ & $-7.56 e-08$ & 2.318 & 9.469 & 3.472 & 10.08 \\
\hline & (9.82e-07) & $(2.71 \mathrm{e}-07)$ & (3.91e-07) & $(17.57)$ & (9.857) & $(17.57)$ & (9.913) \\
\hline \multirow[t]{2}{*}{ HURR_SPAN } & $-0.513^{*}$ & 0.0166 & 0.0260 & $1.994 \mathrm{e}+06$ & 71,559 & $2.403 e+06$ & 308,709 \\
\hline & (0.499) & (0.0710) & $(0.0776)$ & $(2.854 \mathrm{e}+06)$ & $(516,481)$ & $(2.702 e+06)$ & $(486,561)$ \\
\hline GDP & & & & $\begin{array}{c}0.000161 * * * \\
(4.84 \mathrm{e}-05)\end{array}$ & $\begin{array}{c}7.59 \mathrm{e}-05^{* * *} \\
(1.23 \mathrm{e}-05)\end{array}$ & & \\
\hline$N L(S \cup M)$ & & & & & & $\begin{array}{c}36.19 * * * \\
(11.57)\end{array}$ & $\begin{array}{c}15.16 * * * \\
(1.979)\end{array}$ \\
\hline CONS & $\begin{array}{c}2.134 * * * \\
(0.499)\end{array}$ & $\begin{array}{c}-2.278 * * * \\
(0.113)\end{array}$ & $\begin{array}{c}-2.858^{* * *} \\
(0.108)\end{array}$ & $\begin{array}{c}1.190 \mathrm{e}+07^{* *} \\
(4.405 \mathrm{e}+06)\end{array}$ & $\begin{array}{c}3.837 e+06 * * \\
(1.386 e+06)\end{array}$ & $\begin{array}{c}1.261 \mathrm{e}+07^{* * *} \\
(4.395 \mathrm{e}+06)\end{array}$ & $\begin{array}{c}3.947 \mathrm{e}+06 * * * \\
(1.369 \mathrm{e}+06)\end{array}$ \\
\hline Obs. & 29 & 29 & 29 & 29 & 29 & 29 & 29 \\
\hline
\end{tabular}

Note: (a) Columns (1) and (2) use negative binomial and fractional probit models, while columns (3) thru (7) employ ordinary least squares regression analysis; (b) robust standard errors in parentheses; (c) ***,**, and ${ }^{*}$ depict one, five, and ten per cent significance levels. 
Figure 1: GDP - nightlight locus of Caribbean economies

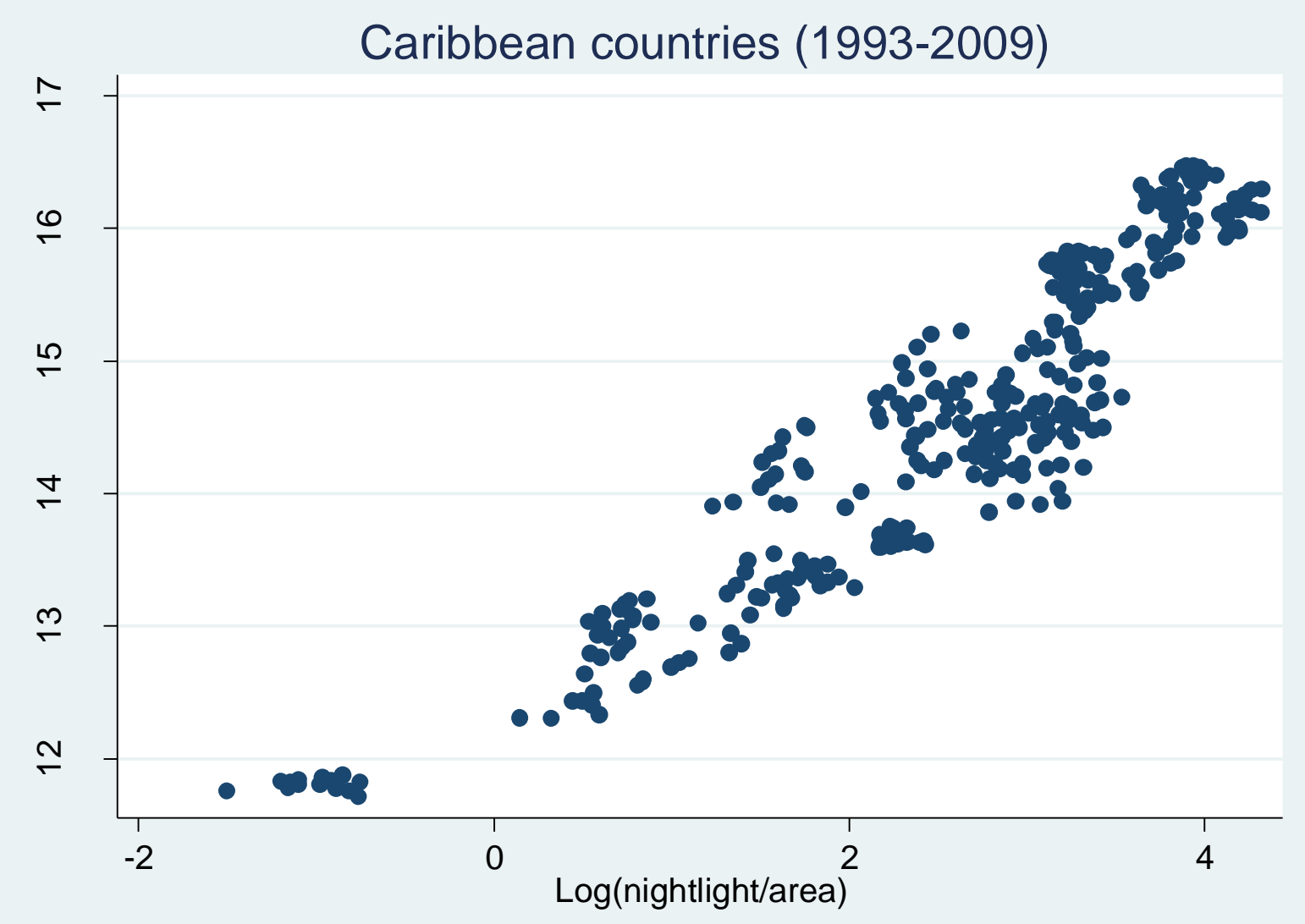


Figure 2: The damage function

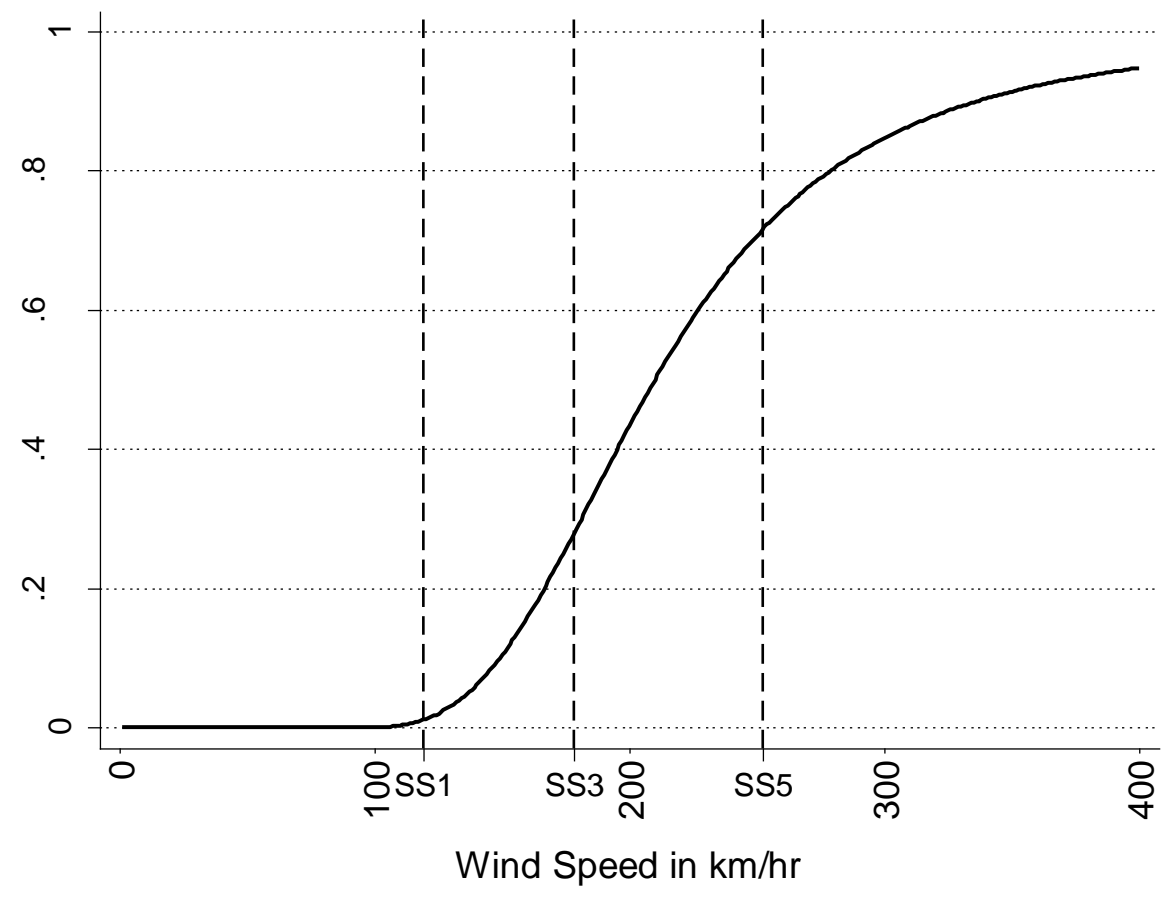


Figure 3: Damage occurrence according to island size

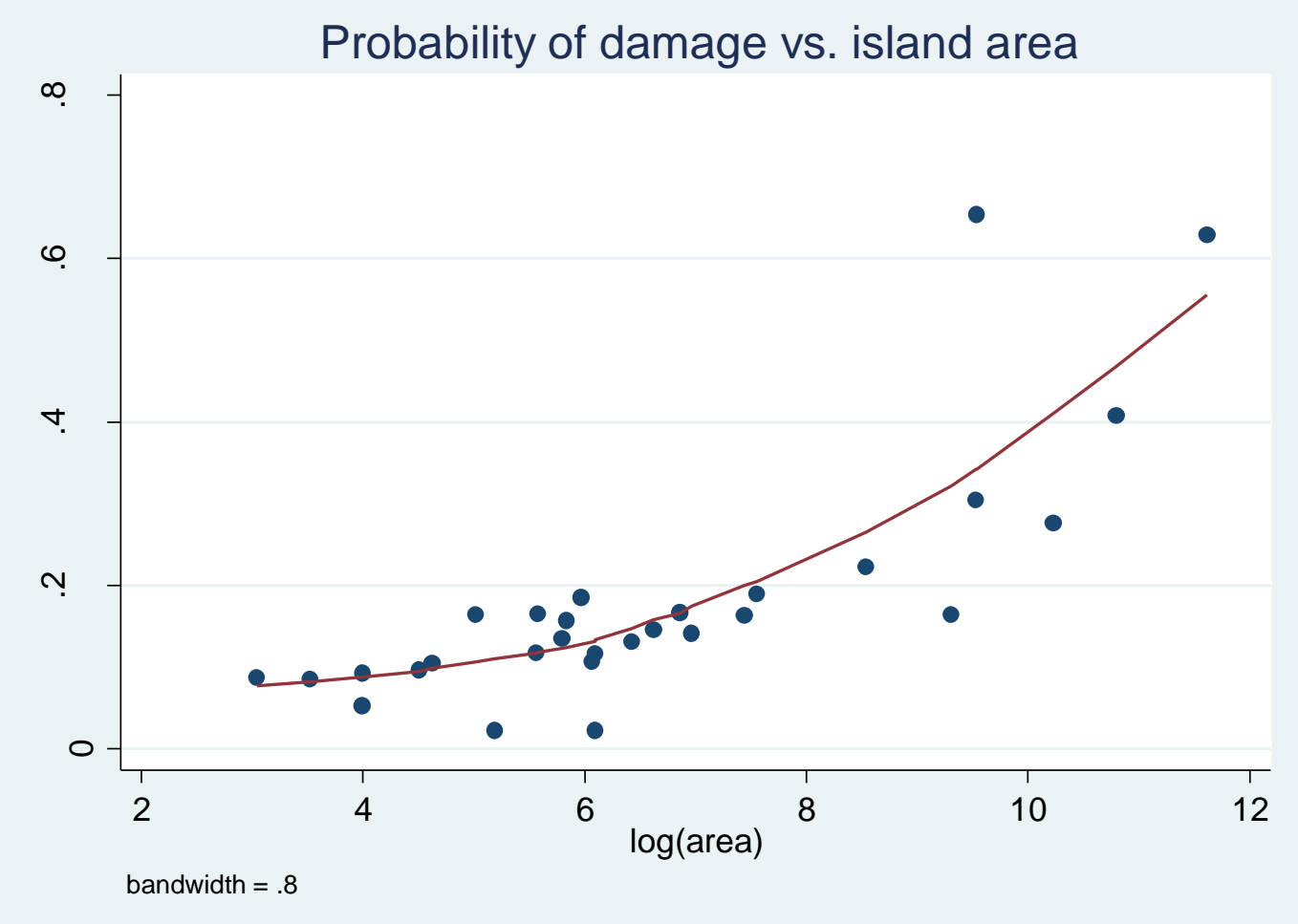

NB: Locally weighted regression of damage proba. on area of island. 


\section{Figures (i)-(IV): Return Period of Damage Index Values}

Figure 4 (i)

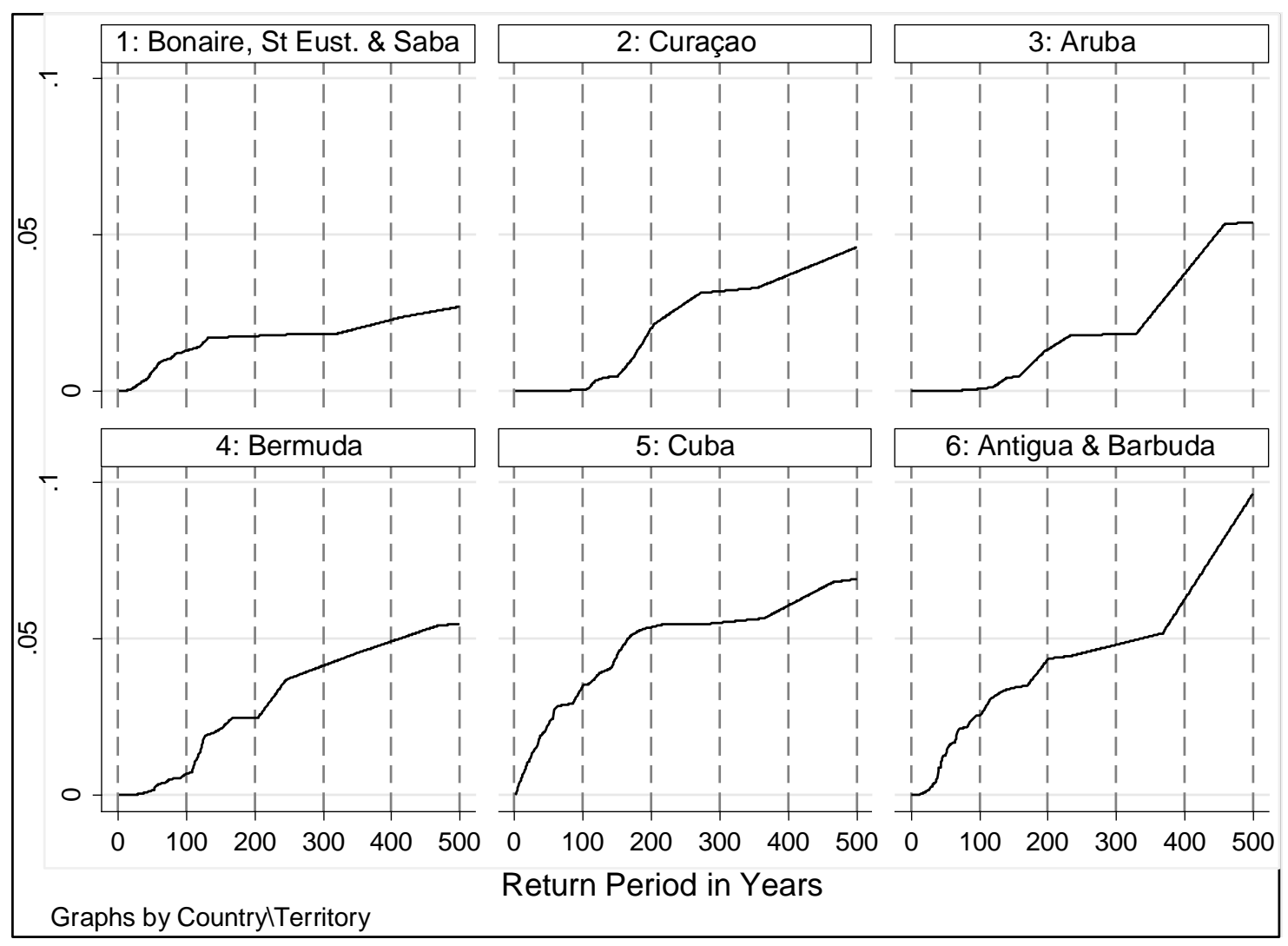




\section{Figure 4 (ii)}

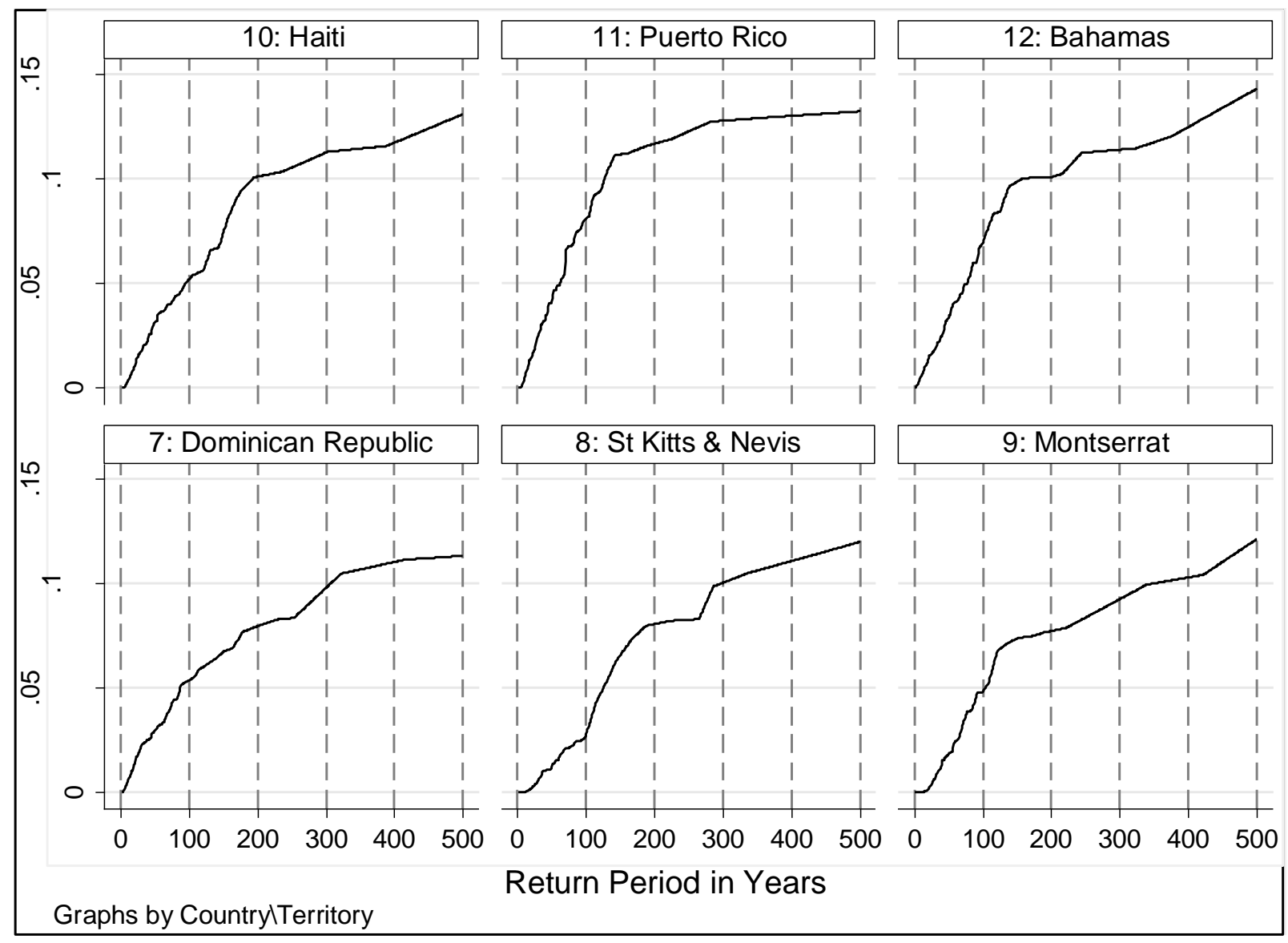




\section{Figure 4 (iii)}

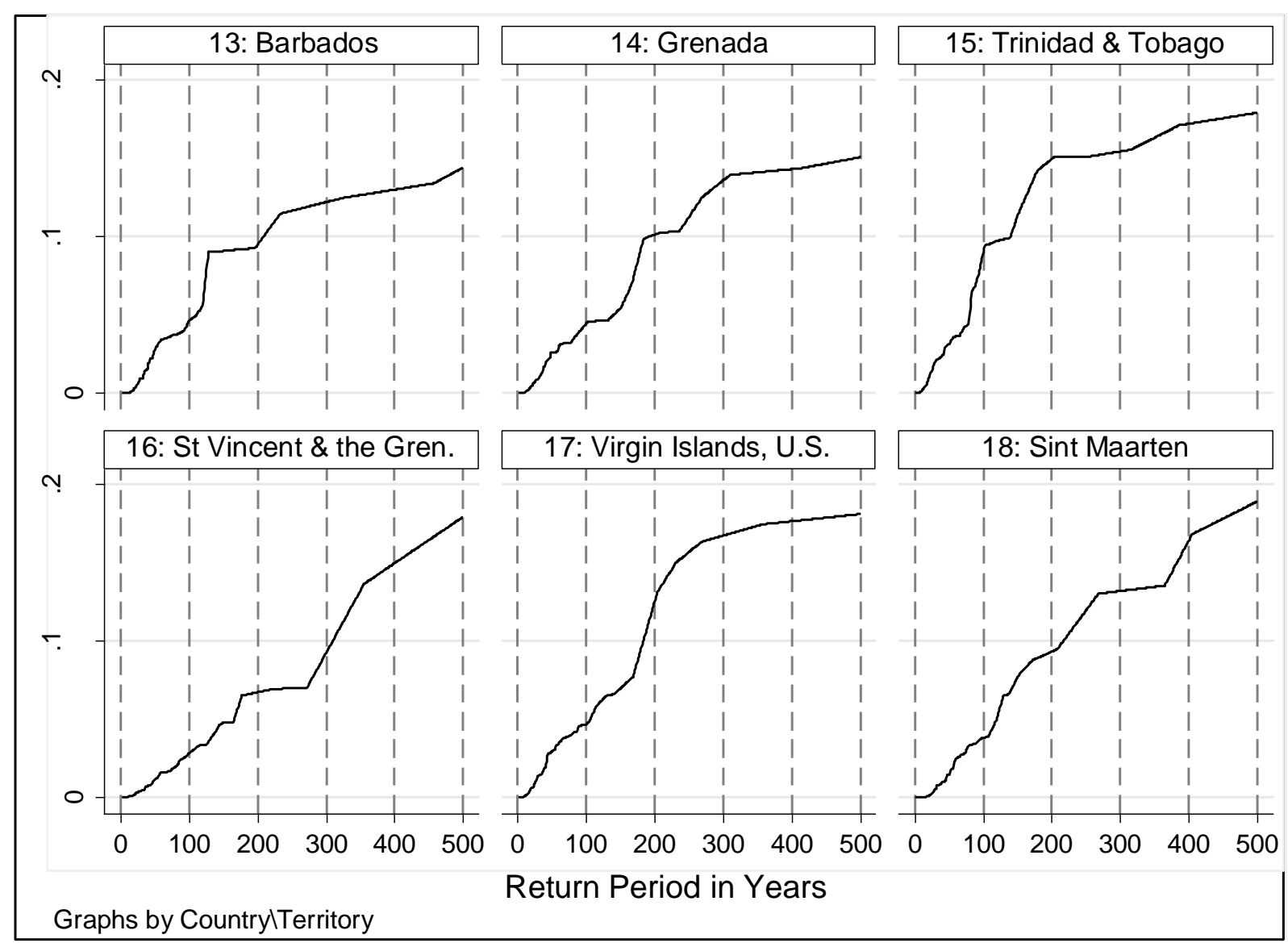




\section{Figure 4 (iv)}

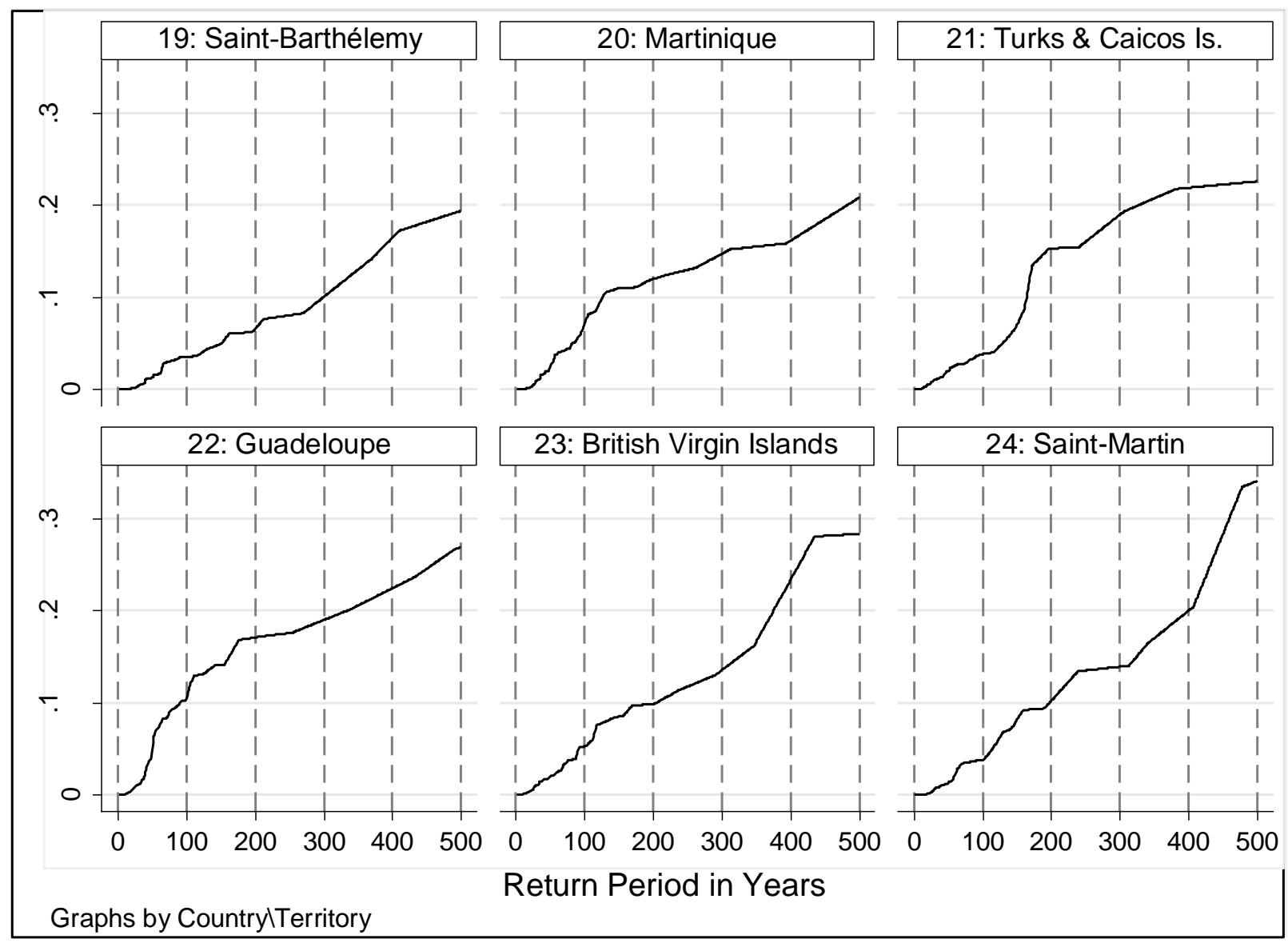


Figure 4 (v)

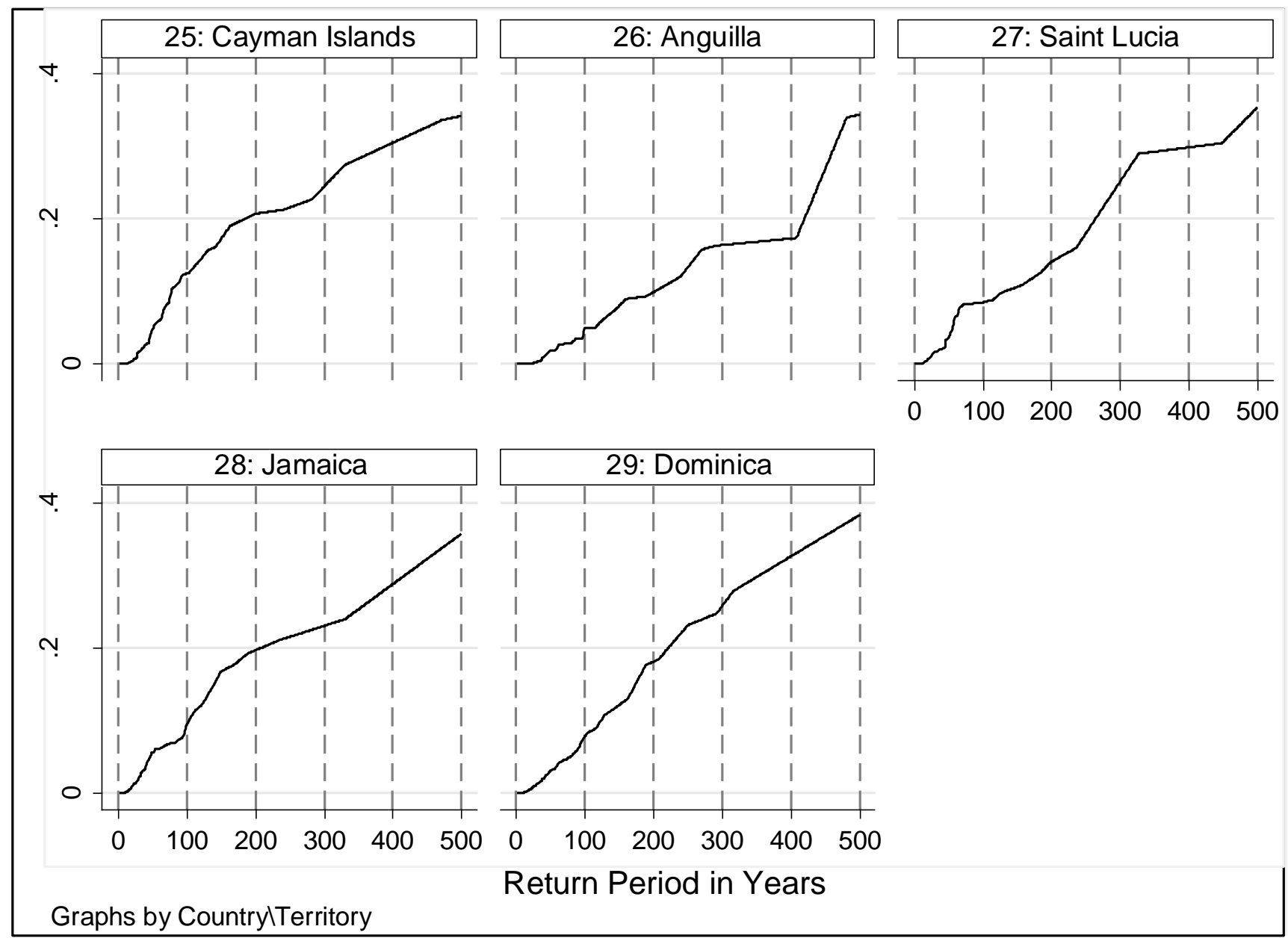


Figure 5: Return Period of Regional Losses

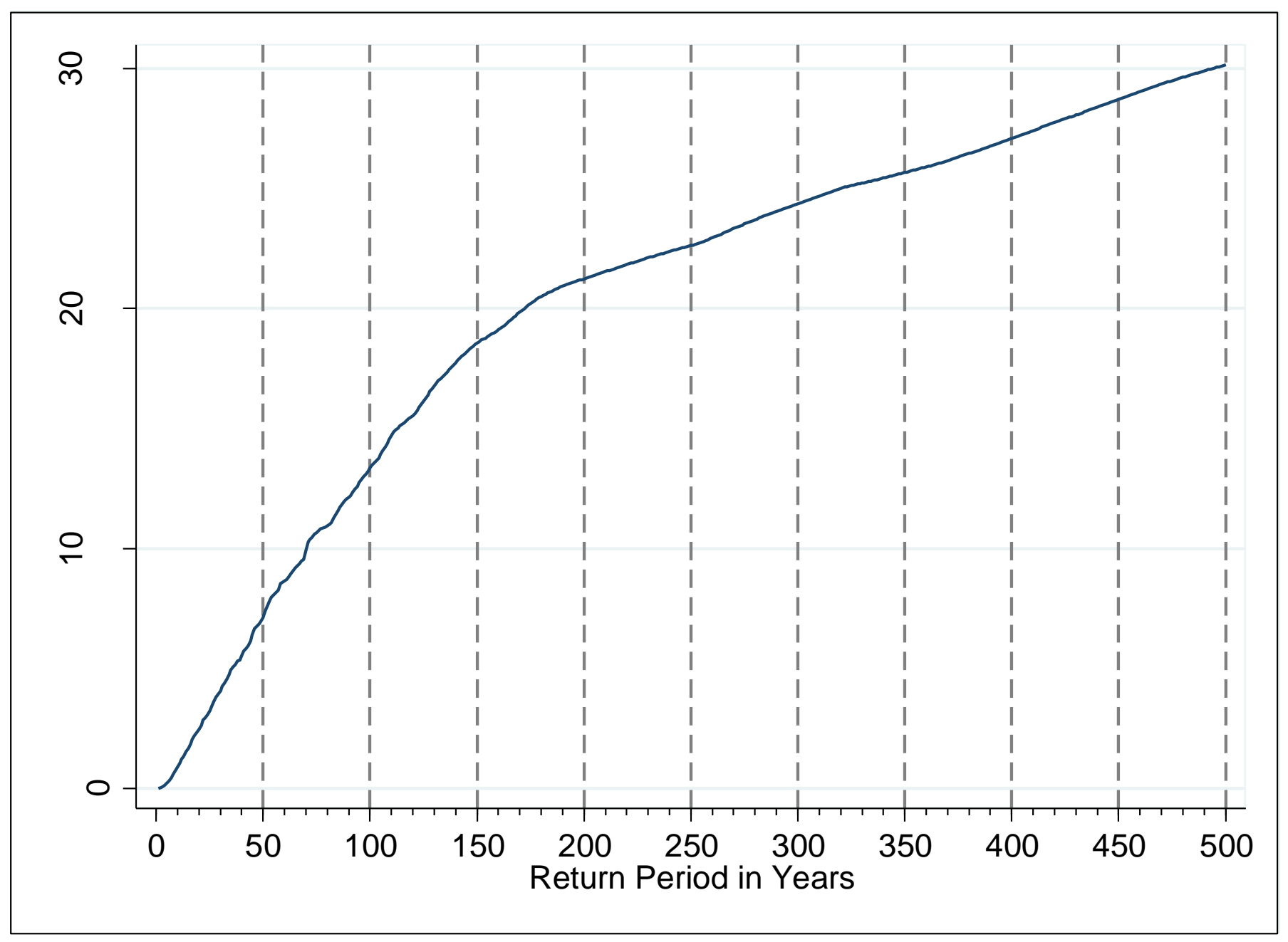

